\title{
Understanding hysteresis in carbon dioxide sorption in porous metal-organic frameworks
}

DOI:

10.1021/acs.inorgchem.9b00016

\section{Document Version}

Accepted author manuscript

Link to publication record in Manchester Research Explorer

\section{Citation for published version (APA):}

Sapchenko, S., Barsukova, M. O., Belosludov, R. V., Kovalenko, K. A., Samsonenko, D. G., Poryvaev, A. S., Sheveleva, A. M., Fedin, M. V., Bogomyakov, A. S., Dybtsev, D. N., Schroder, M., \& Fedin, V. P. (2019). Understanding hysteresis in carbon dioxide sorption in porous metal-organic frameworks. Inorganic Chemistry. https://doi.org/10.1021/acs.inorgchem.9b00016

\section{Published in:}

Inorganic Chemistry

\section{Citing this paper}

Please note that where the full-text provided on Manchester Research Explorer is the Author Accepted Manuscript or Proof version this may differ from the final Published version. If citing, it is advised that you check and use the publisher's definitive version.

\section{General rights}

Copyright and moral rights for the publications made accessible in the Research Explorer are retained by the authors and/or other copyright owners and it is a condition of accessing publications that users recognise and abide by the legal requirements associated with these rights.

\section{Takedown policy}

If you believe that this document breaches copyright please refer to the University of Manchester's Takedown Procedures [http://man.ac.uk/04Y6Bo] or contact uml.scholarlycommunications@manchester.ac.uk providing relevant details, so we can investigate your claim.

\section{OPEN ACCESS}




\title{
Understanding hysteresis in carbon dioxide sorption
}

\section{in porous metal-organic frameworks}

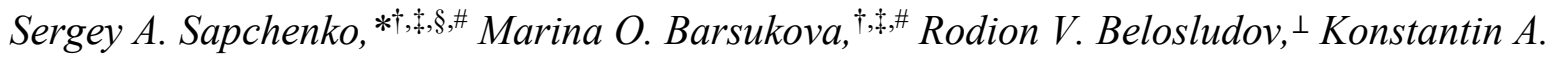

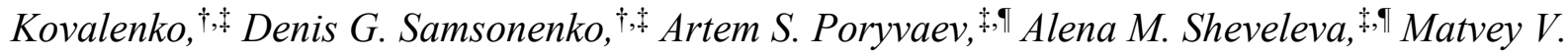 \\ Fedin, Artem S. Bogomyakov, ${ }^{\ddagger}$ Danil N. Dybtsev, ${ }^{\dagger, \grave{\ddagger}}$ Martin Schröder, ${ }^{\S}$ and Vladimir P. \\ Fedin $^{\dagger}+\dot{\dagger}$ \\ $\dagger$ Nikolaev Institute of Inorganic Chemistry, SB RAS, 630090, Novosibirsk, Russia \\ Novosibirsk State University, 630090, Novosibirsk, Russia \\ $\S$ School of Chemistry, University of Manchester, Oxford Road, M13 9PL, Manchester, UK \\ ${ }^{\perp}$ Institute for Materials Research, Tohoku University, 980-8577, Sendai, Japan \\ 『 International Tomography Center SB RAS, 630090, Novosibirsk, Russia
}

\begin{abstract}
Two new isostructural microporous coordination frameworks $\left[\mathrm{Mn}_{3}(\mathrm{Hpdc})_{2}(\mathrm{pdc})_{2}\right](\mathbf{1})$ and $\left[\mathrm{Mg}_{3}(\mathrm{Hpdc})_{2}(\mathrm{pdc})_{2}\right](\mathbf{2})\left(\mathrm{pdc}^{2-}=\right.$ pyridine-2,4-dicarboxylate) showing primitive cubic (pcu) topology have been prepared and characterized. The pore aperture of the channels is too narrow for the efficient adsorption of $\mathrm{N}_{2}$, however, both compounds demonstrate substantially higher
\end{abstract}


uptake of $\mathrm{CO}_{2}\left(119.9 \mathrm{ml} \cdot \mathrm{g}^{-1}\right.$ for $\mathbf{1}$ and $102.5 \mathrm{ml} \cdot \mathrm{g}^{-1}$ for 2 at $195 \mathrm{~K}, 1$ bar). Despite of their structural similarities, 2 shows typical reversible type I isotherm for adsorption/desorption of $\mathrm{CO}_{2}$, while 1 features a two-step adsorption process with a very broad hysteresis between the adsorption and desorption curves. This behavior can be explained by a combination of DFT calculations, sorption and XRD analysis and gives insights to the further development of new sorbents showing adsorption/desorption hysteresis.

\section{INTRODUCTION}

Carbon dioxide $\left(\mathrm{CO}_{2}\right)$ is a major anthropogenic contributor to the greenhouse effect. According to data from the World Meteorological Organization, the quantity of $\mathrm{CO}_{2}$ in the atmosphere has grown at a record speed in 2016 to the highest level in 800000 years, taking $\mathrm{CO}_{2}$ in the atmosphere to $145 \%$ of pre-industrial levels. ${ }^{1}$ To limit global warming to within $2^{\circ} \mathrm{C}$ greenhouse emissions need to be reduced by $40 \%-70 \%$ by 2050 and eliminated completely by $2100 .^{2}$ This will be especially difficult to achieve due to continued reliance upon fossil fuels, and thus the removal of $\mathrm{CO}_{2}$ from the exhaust gas produced by power plants is a methodology to limit the growth of emissions. A typical flue gas contains up to $20 \mathrm{vol}$. \% of carbon dioxide and various chemisorbents and physisorbents for its separation and storage are proposed up to date. Chemisorption based on trapping $\mathrm{CO}_{2}$ with alkali and alkaline earth metal oxides $\left(\mathrm{Na}_{2} \mathrm{O}, \mathrm{CaO}\right.$, $\mathrm{MgO}){ }^{3}$ composites based on aluminum oxide/oxohydroxide, ${ }^{4,5}$ and tantalum oxide $^{6}$ or lithium silicates $^{7}$ have been reported. The use of organic bases such as monoethanolamine (MEA), diethanolamine (DEA) and methyldiethanolamine (MDEA) in aqueous solution is another effective method for chemical capture of $\mathrm{CO}_{2} .^{8}$ 
Capture and separation of $\mathrm{CO}_{2}$ by physisorption involves weaker bonding energetics and can thus be applied to cyclic adsorption/desorption processes, with desorption induced by changes in pressure or by heating. Zeolites, ${ }^{9-11}$ activated carbon, ${ }^{12,13}$ metal-organic frameworks (MOFs) ${ }^{14-18}$ zeolitic imidazolate frameworks (ZIFs) ${ }^{19}$ and covalent-organic frameworks materials (COFs) ${ }^{20-22}$ are the most prominent solid adsorbents considered for $\mathrm{CO}_{2}$ capture by physisorption. Many of these materials demonstrate one-step type I sorption isotherms with $\mathrm{CO}_{2}$ indicating a typical Langmuir sorption mechanism. Recently, McDonald et al. demonstrated the advantages of sorbent exhibiting stepped isotherms, with S-shaped hysteresis for $\mathrm{CO}_{2}$ uptake and release. ${ }^{23} \mathrm{In}$ contrast to classical solid sorbents and reference amine systems, materials showing significant hysteresis can be regenerated with lower energy penalties and have greater working capacities. Thus, the development of solid-state materials showing hysteresis is highly desirable for efficient $\mathrm{CO}_{2}$ uptake and capture; however, the systematic design of such systems is restrained by lack of understanding of the mechanisms leading to the high hysteresis in $\mathrm{CO}_{2}$ sorption.

We report the synthesis and characterization of two multifunctional porous MOF complexes, $\left[\mathrm{Mn}_{3}(\mathrm{Hpdc})_{2}(\mathrm{pdc})_{2}\right](\mathbf{1})$ and its isostructural analogue $\left[\mathrm{Mg}_{3}(\mathrm{Hpdc})_{2}(\mathrm{pdc})_{2}\right](\mathbf{2})\left(\mathrm{pdc}^{2-}\right.$ is pyridine2,4-dicarboxylate). In spite of their close structural similarities, 2 shows rather typical reversible $\mathrm{CO}_{2}$ adsorption isotherm while 1 features extremely high adsorption/desorption hysteresis and high selectivity to $\mathrm{CO}_{2}$ over $\mathrm{N}_{2}$ and $\mathrm{CH}_{4}$. A detailed investigation of their gas sorption, magnetic and luminescent properties allowed us to determine the fundamental mechanism of the surprisingly high $\mathrm{CO}_{2}$ hysteresis in $\mathbf{1}$ by a combination of experimental and theoretical methods. 


\section{EXPERIMENTAL SECTION}

Materials and Measurements. All reagents and solvents were commercially available and used as supplied without further purification. The FTIR spectra were recorded from $\mathrm{KBr}$ pellets in the range 4000-400 $\mathrm{cm}^{-1}$ on Scimitar FTS 2000 Fourier-transform infrared spectrometer. Thermogravimetric analysis (TGA) was performed using TG 209 F1 Iris Thermo Microbalance (NETZSCH) instrument at temperatures between 25 and $600^{\circ} \mathrm{C}$ under $\mathrm{He}$ atmosphere at a heating rate of $10^{\circ} \mathrm{C} / \mathrm{min}$. Powder X-ray diffraction (PXRD) patterns were measured with $\mathrm{Cu}-\mathrm{K} \alpha$ radiation on a Shimadzu XRD 7000S powder X-ray diffractometer. Elemental analyses (C, H, N) were performed on the Euro EA 3000 CHN Elemental Analyzer.

$\left[\mathbf{M n}_{3}(\mathbf{H p d c})_{2}(\mathbf{p d c})_{2}\right] \cdot \mathbf{4 . 8 D M F} \cdot \mathrm{H}_{2} \mathrm{O}(\mathbf{1})$. Pyridine-2,4-dicarboxylic acid monohydrate $\left(\mathrm{H}_{2} \mathrm{pdc}\right)$ (185 mg, $1 \mathrm{mmol}), \mathrm{MnCl}_{2} \cdot 4 \mathrm{H}_{2} \mathrm{O}(148 \mathrm{mg}, 0.75 \mathrm{mmol})$ and triethylamine $(2 \mathrm{mmol}, 280 \mu \mathrm{l})$ were dissolved in N,N-dimethylformamide (DMF) (20 mL) containing concentrated $\mathrm{HCl}$ (15 drops) in a $25 \mathrm{~mL}$ screwed-cap glass vial. The reaction was heated at $100{ }^{\circ} \mathrm{C}$ for 3 days and the mixture cooled to room temperature. The yellow crystals were filtered and washed with DMF $(1 \mathrm{ml})$ three times. Yield: $47 \%$ (based on $\mathrm{Mn}$ ). Elemental analysis. Calcd (\%) for $\mathrm{C}_{42.4} \mathrm{H}_{49.6} \mathrm{Mn}_{3} \mathrm{~N}_{8.8} \mathrm{O}_{21.8}$ : C 42.8, H 4.2, $\mathrm{N}$ 10.3; found (\%): C 43.5, H 4.6, $\mathrm{N}$ 9.9. IR spectra see

Figure S1. Phase purity of the crystals was confirmed by powder X-ray diffraction (PXRD) (Figure S1).

$\left[\mathbf{M g}_{3}(\mathrm{Hpdc})_{2}(\mathbf{p d c})_{2}\right] \cdot 4 \mathrm{DMF} \cdot \mathrm{H}_{2} \mathrm{O}$ (2). 2 was obtained according to the procedure used for compound 1. Pyridine-2,4-dicarboxylic acid monohydrate ( $\left.\mathrm{H}_{2} \mathrm{pdc}\right)(185 \mathrm{mg}, 1 \mathrm{mmol}$ ), $\mathrm{Mg}\left(\mathrm{NO}_{3}\right)_{2} \cdot 6 \mathrm{H}_{2} \mathrm{O}(128 \mathrm{mg}, 0.5 \mathrm{mmol})$ and triethylamine $(2 \mathrm{mmol}, 280 \mu \mathrm{l})$ were dissolved in $\mathrm{N}, \mathrm{N}-$ dimethylformamide (DMF) $(20 \mathrm{~mL})$ containing concentrated $\mathrm{HCl}(15$ drops $)$ in a $25 \mathrm{~mL}$ screwed-cap glass vial. The reaction was heated at $100{ }^{\circ} \mathrm{C}$ for 3 days and the mixture cooled to 
room temperature. The colorless crystals were filtered and washed with DMF $(1 \mathrm{ml})$ three times. Yield: $45 \%$ (based on $\mathrm{Mg}$ ). Elemental analysis. Calcd (\%) for $\mathrm{C}_{40} \mathrm{H}_{46} \mathrm{Mg}_{3} \mathrm{~N}_{8} \mathrm{O}_{22}$ : C 45.2, H 4.4, N 10.5; found (\%): C 46.0, H 5.0, N 10.2. IR spectra see Figure S1. Phase purity of the crystals was confirmed by powder X-ray diffraction (PXRD) (Figure S1).

Crystallographic studies. Single crystal X-ray diffraction data of 1 were collected at $150 \mathrm{~K}$ on a Bruker Apex Duo automatic four-circle diffractometer equipped with an area detector $(\mathrm{Cu}-$ $\mathrm{K} \alpha, \lambda=1.54178 \AA$, graphite monochromator, $\varphi$ and $\omega$ scans). Data collection, frame integration, and data processing were performed with the use of the APEX2 and SAINT program packages. ${ }^{24}$ The absorption correction was applied based on the intensities of equivalent reflections with the use of the SADABS program. ${ }^{24}$ The structure was solved by direct method and refined on $F^{2}$ by full-matrix least-squares method in the anisotropic approximation (for non-hydrogen atoms) using SHELX-2014 program package. ${ }^{25}$ The positions of hydrogen atoms of organic ligands were calculated geometrically and refined by a riding model. Guest DMF and water molecules in the structure $\mathbf{1}$ are highly disordered and were not refined as a set of discrete atoms. The PLATON/SQUEEZE ${ }^{26}$ procedure was applied to calculate the contribution to the diffraction from the solvent region and thereby produced a set of solvent-free diffraction intensities. The final composition of the compound was calculated taking into account the SQUEEZE results (333 $e^{-}$in $\left.1235.3 \AA^{3}\right)$. Residual electron density $\left(3.19 e / \AA^{3}\right)$ in the structure of $\mathbf{1}$ is situated close to $\mathrm{Mn}(2)$ and $\mathrm{O}(21)$ atoms $(1.65-1.18 \AA)$. A summary of the crystallographic data and structural determination for $\mathbf{1}$ is provided in Table S1, and selected bond length and angles are listed in Table S2. The unit cell parameters calculated from PXRD data are given in Table S3. 
CCDC 1853065 contains the supplementary crystallographic data for this paper. These data can be obtained free of charge from The Cambridge Crystallographic Data Center at http://www.ccdc.cam.ac.uk/data_request/cif.

DFT calculations: First-principles calculations were performed within the framework of density functional theory (DFT) as implemented in the Vienna Ab initio Simulation Package (VASP). ${ }^{27,28}$ The Perdew, Burke, and Ernzerhof (PBE) parameterization of generalized gradient approximation (GGA) and the all-electron projector augmented wave (PAW) method to model the interactions between the ion cores were used..$^{29,30}$ The plain-wave cutoff energy was $400 \mathrm{eV}$ and convergence in energy $\left(10^{-4} \mathrm{eV}\right)$ and force $\left(3 \times 10^{-3} \mathrm{eV} / \AA\right)$ were used during the optimization procedure. Monkhorst-Pack $k$-point mesh of $3 \times 3 \times 3$, was used for Brillouin zone integration, ${ }^{31}$ and the semiempirical dispersive van der Waals (vdW) interaction was taken into account using the Grimme parametrization. ${ }^{32}$ The difference between the energy of adsorbed system ( $\left.E_{\text {host }+ \text { guest }}\right)$ and the sum of the energies of the empty metal-organic framework ( $\left.E_{\text {host }}\right)$ and the number of non-coordinated guest molecules $\left(n * E_{\text {guest }}\right)$, with $n$ equal to the number of adsorbed molecules was used in order to estimate the adsorption energies $\left(E_{a d s}\right)$ using the following expression

$$
E_{\text {ads }}=E_{\text {host }}+\text { guest }-\left(E_{\text {host }}+n * E_{\text {guest }}\right) \text {. }
$$

A negative value of $E_{a d s}$ indicates that the adsorption state is thermodynamically favourable. The host-guest interaction has been demonstrated by the difference in charge density (excess and depletion electrons) given by

$$
\Delta \rho=\rho(\text { host }+ \text { guest })-\rho \text { (host })-\sum_{k=1}^{n} \rho_{k} \text { (guest) }
$$


All structures of the MOF with adsorbed guest molecules as well as the obtained charge density isosurfaces for the guest-host interactions were visualized by using VESTA code. ${ }^{33}$ The methods and theoretical analysis described have been verified in our previous studies of gas sorption into MOF structures. ${ }^{34,35}$ The effective charge of atoms was evaluated by using the Bader analysis algorithm. ${ }^{36-39}$

Luminescence studies. The excitation and emission spectra of the solid samples were recorded on a Cary Eclipse (Varian) fluorescence spectrophotometer. The emission spectra of the complexes were recorded at room temperature under the following experimental conditions: $\mathrm{V}=$ $500 \mathrm{~V}$, spectral slit width $=5 \mathrm{~nm}$. The Xenon flash lamp was used as a light source to excite the steady-state PL spectra.

Activation procedure. Crystals of $\mathbf{1}$ and $\mathbf{2}$ were soaked in acetone for 3 days, dried and placed under vacuum at room temperature for $12 \mathrm{~h}$ in a Quantachrome Autosorb iQ volumetric instrument. The activated compounds retain their crystallinity after sorption experiments, according to PXRD (Figure S2).

Gas adsorption studies. Gas isotherms were measured on a Quantachrome Autosorb iQ volumetric instrument using a cryocooler. $\mathrm{N}_{2}$ at $77 \mathrm{~K}$ and $\mathrm{CO}_{2}$ at $195 \mathrm{~K}$ sorption-desorption isotherms were measured in the range $10^{-4}$ to 1 bar.

In situ Synchrotron Powder X-ray Diffraction (PXRD). In situ PXRD experiments were carried out at Beamline I11 Diamond Light Source (Oxford, UK) as a function of $\mathrm{CO}_{2}$ loading using high-resolution synchrotron diffraction $(\lambda=0.825774 \AA)$. The sample was loaded into capillary gas cell, and the temperature controlled by an Oxford open-flow Cryosystems. Activated $\mathbf{1}$ was generated by heating the sample in situ under vacuum overnight. The resultant PXRD was measured at $0,0.25,0.5$ and 1 bar of $\mathrm{CO}_{2}$ pressure at $195 \mathrm{~K}$. 
Magnetic measurements. The magnetic susceptibility of the polycrystalline samples was measured on a Quantum Design MPMSXL SQUID magnetometer over the temperature range 2$300 \mathrm{~K}$ with magnetic field of up to $5 \mathrm{kOe}$. Diamagnetic corrections were made using the Pascal constants. The effective magnetic moment was calculated as

$$
\mu_{\mathrm{eff}}(\mathrm{T})=\left[\left(3 \mathrm{k} / \mathrm{N}_{\mathrm{A}} \mu_{\mathrm{B}}{ }^{2}\right) \chi T\right]^{1 / 2} \approx(8 \chi T)^{1 / 2}
$$

EPR measurements. Polycrystalline powder $(5 \mathrm{mg})$ of activated compound was placed in the an EPR sample tube (OD $2.8 \mathrm{~mm}$ ID $1.8 \mathrm{~mm}$ ) and evacuated at room temperature and low pressure $\left(10^{-5}\right.$ torr) over $24 \mathrm{~h}$. The desired amount of gas was introduced and the sample cooled with liquid $\mathrm{N}_{2}$ and the sample was sealed. All data were obtained using Bruker ELEXYS E580 spectrometer at Q-band $(\approx 34 \mathrm{GHz})$ equipped with temperature control system. The best trade-off between sensitivity, resolution and avoiding saturation was found by measuring FID-detected EPR spectra at $20 \mathrm{~K}$, and then applying pseudomodulation of $0.1 \mathrm{mT}$. Figure S9 shows qualitative simulation of the FID-detected EPR spectra of samples $\mathbf{1}$ and $\mathbf{3}$. In both cases, in agreement with structural data, model assumes superposition of two centers: $\mathrm{MnO}_{6}$ with only ${ }^{55} \mathrm{Mn}$ hyperfine interaction (HFI) constant, and $\mathrm{MnO}_{4} \mathrm{~N}_{2}$ with ${ }^{55} \mathrm{Mn}$ HFI and two ${ }^{14} \mathrm{~N}$ HFIs. The calculated spectra were obtained using the following parameters:

$\mathrm{MnO}_{6}$ unit: $\mathrm{A}\left({ }^{55} \mathrm{Mn}\right)=9.0 \mathrm{mT}, g=2.002$.

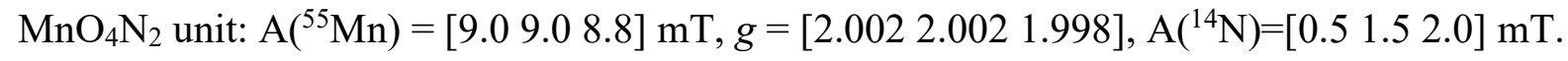

To simulate broadening of the spectrum of samples 3 vs. 1, we imposed additional line broadening in 3 equivalent of the linewidth of $0.5 \mathrm{mT}$. 


\section{RESULTS AND DISCUSSION}

Yellow prismatic crystals of $\left[\mathrm{Mn}_{3}(\mathrm{Hpdc})_{2}(\mathrm{pdc})_{2}\right] \cdot 4.8 \mathrm{DMF} \cdot \mathrm{H}_{2} \mathrm{O} \quad\left(\mathbf{1} \cdot 4.8 \mathrm{DMF} \cdot \mathrm{H}_{2} \mathrm{O}\right)$ were obtained by heating $\mathrm{MnCl}_{2} \cdot 4 \mathrm{H}_{2} \mathrm{O}$ and 2,4-pyridinedicarboxylic acid in the presence of small amounts of triethylamine in a slightly acidified $\mathrm{N}, \mathrm{N}$-dimethylformamide. $1 \cdot 4.8 \mathrm{DMF} \cdot \mathrm{H}_{2} \mathrm{O}$ crystallizes in the orthorhombic space group Pba2 (Table S1), and comprises two crystallographically independent $\mathrm{Mn}$ (II) ions and two pyridinedicarboxylate ligands (Figure 1).

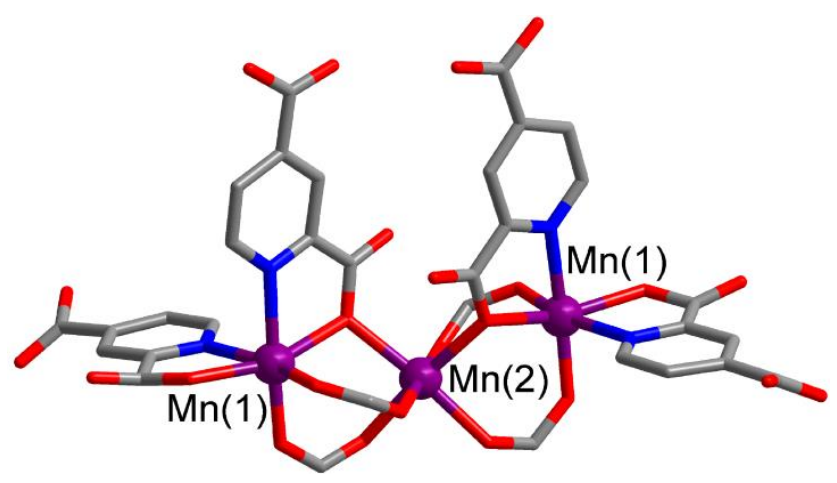

Figure 1. Structure of secondary building unit in $\left[\mathrm{Mn}_{3}(\mathrm{Hpdc})_{2}(\mathrm{pdc})_{2}\right](\mathbf{1})$.

The $\mathrm{Mn}(\mathrm{II})$ centers show distorted octahedral coordination with $\mathrm{Mn}(1)$ bound to four $\mathrm{O}$ and two $\mathrm{N}$ centres, and $\mathrm{Mn}(2)$ bound to six $\mathrm{O}$ atoms from six pyridinedicarboxylate ligands. All the $\mathrm{Mn}-\mathrm{N}$ and $\mathrm{Mn}-\mathrm{O}$ bond lengths fall within the range for other octahedral complexes of $\mathrm{Mn}(\mathrm{II})$ (Table S2). Each $\mathrm{Mn}(2)$ center connects to two $\mathrm{Mn}(1)$ atoms via $\mu$-carboxylate groups to form a trinuclear $\left\{\mathrm{Mn}_{3}(\mathrm{OOC})_{6} \mathrm{~N}_{6}\right\}$ unit, which can be regarded as 6-connected node bound to $\mathrm{Hpdc}^{-}$ $/ \mathrm{pdc}^{2-}$ linkers into layers in the $a b$ plane. Another $\mathrm{pdc}^{2-}$ ligand connects these layers in three dimensions to give a framework of pcu topology, which comprises a system of intersected channels with an aperture of $3 \times 6 \AA$ (Figure 2). 


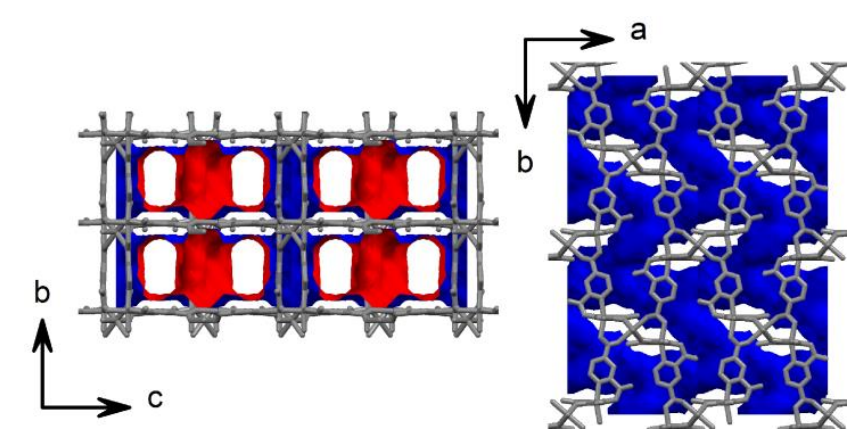

Figure 2. View of the pore in $\left[\mathrm{Mn}_{3}(\mathrm{Hpdc})_{2}(\mathrm{pdc})_{2}\right](\mathbf{1})$ along the $a$ and $c$ axes.

The free accessible volume estimated by PLATON ${ }^{26}$ is $49 \%$. In the as-synthesized material the pores are filled with disordered solvent molecules of DMF and $\mathrm{H}_{2} \mathrm{O}$. According to the TGA and elemental analytical data and the results of the SQUEEZE procedure ${ }^{26}$ the chemical composition of the as-synthesized form is $\left[\mathrm{Mn}_{3}(\mathrm{Hpdc})_{2}(\mathrm{pdc})_{2}\right] \cdot 4.8 \mathrm{DMF} \cdot \mathrm{H}_{2} \mathrm{O}$. The phase purity of the bulk sample of compound $1 \cdot 4.8 \mathrm{DMF} \cdot \mathrm{H}_{2} \mathrm{O}$ was confirmed by PXRD (Figure $\mathrm{S} 1$ ). It is important to note that the charge balance of $\mathbf{1}$ was unambiguously assigned to a combination of $\mathrm{pdc}^{2-}$ and $\mathrm{Hpdc}^{-}$ligands rather than to higher oxidation $\mathrm{Mn}(\mathrm{III})$ or $\mathrm{Mn}(\mathrm{IV})$ states by magnetic measurements (vide infra) and by bond valence sum analysis. ${ }^{40}$

The colorless microcrystalline $\left[\mathrm{Mg}_{3}(\mathrm{Hpdc})_{2}(\mathrm{pdc})_{2}\right] \cdot 4 \mathrm{DMF} \cdot 2 \mathrm{H} 2 \mathrm{O} \quad\left(\mathbf{2} \cdot 4 \mathrm{DMF} \cdot 2 \mathrm{H}_{2} \mathrm{O}\right)$ was obtained under analogous reaction conditions to 1 using $\mathrm{Mg}\left(\mathrm{NO}_{3}\right)_{2}$ as a metal source. The PXRD patterns for $\mathbf{2}$ and $\mathbf{1}$ coincide, confirming the isostructural nature of both compounds (Figure S1). The indexing of the peaks gave very similar unit cell parameters (Table S3).

1 and 2 show similar thermal behavior (Figure S4) under He with weight loss occurring in up to 320 and $300^{\circ} \mathrm{C}$, respectively, assigned to the loss of guest water and DMF molecules. Both compounds demonstrate the same weight loss of $31 \%$ consistent with their formulation. This first 
weight loss is followed by a plateau region ranging up to 400 and $460^{\circ} \mathrm{C}$ for $\mathbf{1}$ and $\mathbf{2}$, respectively, confirming their chemical with further heating leading to decomposition of the frameworks.

As might be expected for materials containing different metal cations, $\mathbf{1}$ and $\mathbf{2}$ show different luminescent properties. The excitation and emission spectra are displayed on Figure 3. For assynthesized 1, the emission spectrum displays a greenish-yellow color with a broad band centered at $580 \mathrm{~nm}$ assigned to a ligand-to-metal electronic transition. The emission spectra of as-synthesized 2 shows band at $420 \mathrm{~nm}$, assigned to intra-ligand pyridinedicarboxylate-centered electronic transition. Thus, the electron ligand-to-metal charge transfer was observed only in the case of compound $\mathbf{1}$, since $d$-orbitals of Mn centers can participate in the charge transfer, ${ }^{41,42}$ while charge-transfer emission is not characteristic for the compounds of $s$-elements such as $\mathrm{Mg}$.

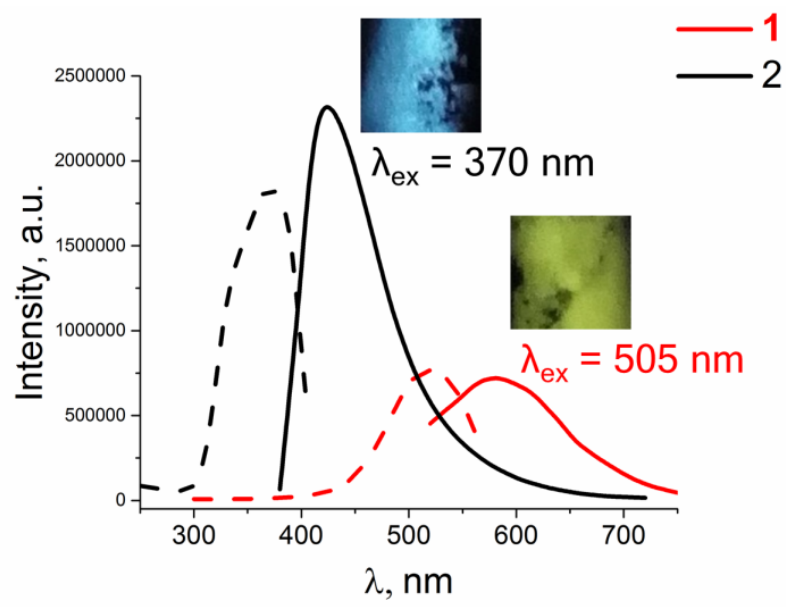

Figure 3. Solid-state luminescence spectra of $\left[\mathrm{Mn}_{3}(\mathrm{Hpdc})_{2}(\mathrm{pdc})_{2}\right] \mathbf{1}\left(\lambda_{\mathrm{ex}}=505 \mathrm{~nm}\right)$ and $\left[\mathrm{Mg}_{3}(\mathrm{Hpdc})_{2}(\mathrm{pdc})_{2}\right] \mathbf{2}\left(\lambda_{\mathrm{ex}}=370 \mathrm{~nm}\right)$. Excitation spectra are shown with dashed lines; emission spectra are shown with solid lines.

Removal of guest water and DMF molecules was achieved by soaking $\mathbf{1}$ and $\mathbf{2}$ in acetone for several days and then placed under vacuum at ambient conditions. The PXRD pattern (Figure 
S2) and elemental analytical data confirm removal of guest molecules and retention of the framework structure after sorption. However, $\mathrm{N}_{2}$ sorption experiments at $77 \mathrm{~K}$ (Figure S5) show very low adsorption even at 1 bar, with uptakes of $36.4 \mathrm{~mL} / \mathrm{g}$ for $\mathbf{1}$ and $32.5 \mathrm{~mL} / \mathrm{g}$ for $\mathbf{2} . \mathrm{CO}_{2}$ has a smaller kinetic diameter than $\mathrm{N}_{2}$, and $\mathrm{CO}_{2}$ uptake was found to be $119.9 \mathrm{~mL} / \mathrm{g}$ for $\mathbf{1}$ and 102.5 $\mathrm{mL} / \mathrm{g}$ for $\mathbf{2}$ at $195 \mathrm{~K}$ and 1 bar (Figure 4).

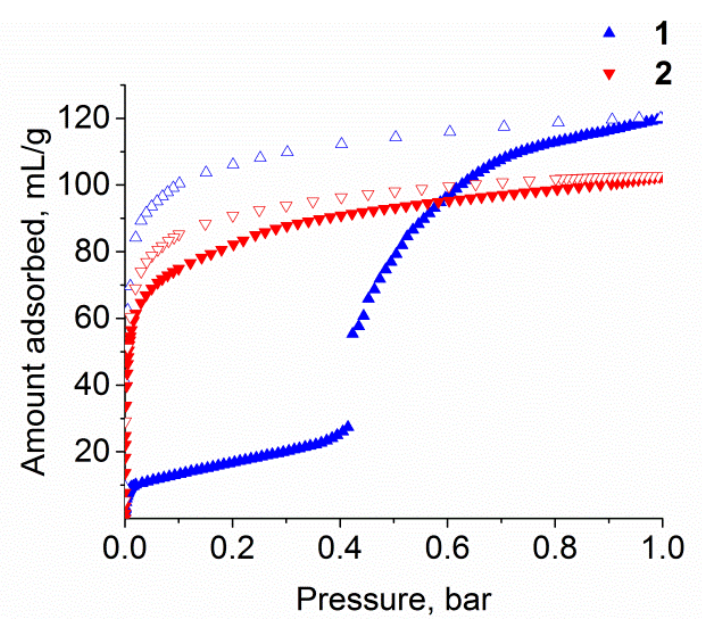

Figure 4. View of the adsorption (filled symbols) and desorption (open symbols) isotherms at $195 \mathrm{~K}$ for $\mathrm{CO}_{2}$ in $\left[\mathrm{Mn}_{3}(\mathrm{Hpdc})_{2}(\mathrm{pdc})_{2}\right] \mathbf{1}$ (blue triangles) and $\left[\mathrm{Mg}_{3}(\mathrm{Hpdc})_{2}(\mathrm{pdc})_{2}\right] \quad 2$ (red triangles).

For 2 the $\mathrm{CO}_{2}$ sorption isotherm at $195 \mathrm{~K}$ has a typical type I shape with a small degree of sorption/desorption hysteresis. The BET surface area for 2 was measured as $383 \mathrm{~m}^{2} \cdot \mathrm{g}^{-1}$ (Table 1). The general shape of the isotherm does not change with increasing temperature and only leads to the expectedly lower $\mathrm{CO}_{2}$ uptake (Figure 5). Overall, 2 demonstrates the classical behavior of a microporous solid. However, the sorption isotherm for $\mathrm{CO}_{2}$ in $\mathbf{1}$ collected at various temperatures has a stepwise S-shaped form with a very large hysteresis loop, which is less common for microporous materials (Figure 5). 
Table 1. Parameters for the porous structures $\mathbf{1}$ and $\mathbf{2 .}$

\begin{tabular}{|c|c|c|c|c|c|c|}
\hline \multirow{2}{*}{ Compound } & \multicolumn{3}{|c|}{ Specific surface area $/ \mathrm{m}^{2} \cdot \mathrm{g}^{-1}$} & \multicolumn{2}{|c|}{$V_{\text {pore }} / \mathrm{cm}^{3} \cdot \mathrm{g}^{-1}$} & \multirow{2}{*}{$\begin{array}{l}V_{\mathrm{ads}}\left(\mathrm{N}_{2}\right)^{a} / \\
\mathrm{cm}^{3}(\mathrm{STP}) \cdot \mathrm{g}^{-1}\end{array}$} \\
\hline & Langmuir & BET & DFT & Gourvich & DFT & \\
\hline 1 & $594^{b}$ & $520^{b}$ & 107 & 0.251 & 0.023 & 120 \\
\hline 2 & $476^{b}$ & $383^{b}$ & 660 & 0.215 & 0.149 & 102 \\
\hline
\end{tabular}

\footnotetext{
${ }^{a}$ measured or calculated at $P=1$ bar

${ }^{b}$ calculated from desorption curve for $\mathrm{CO}_{2}$.
}
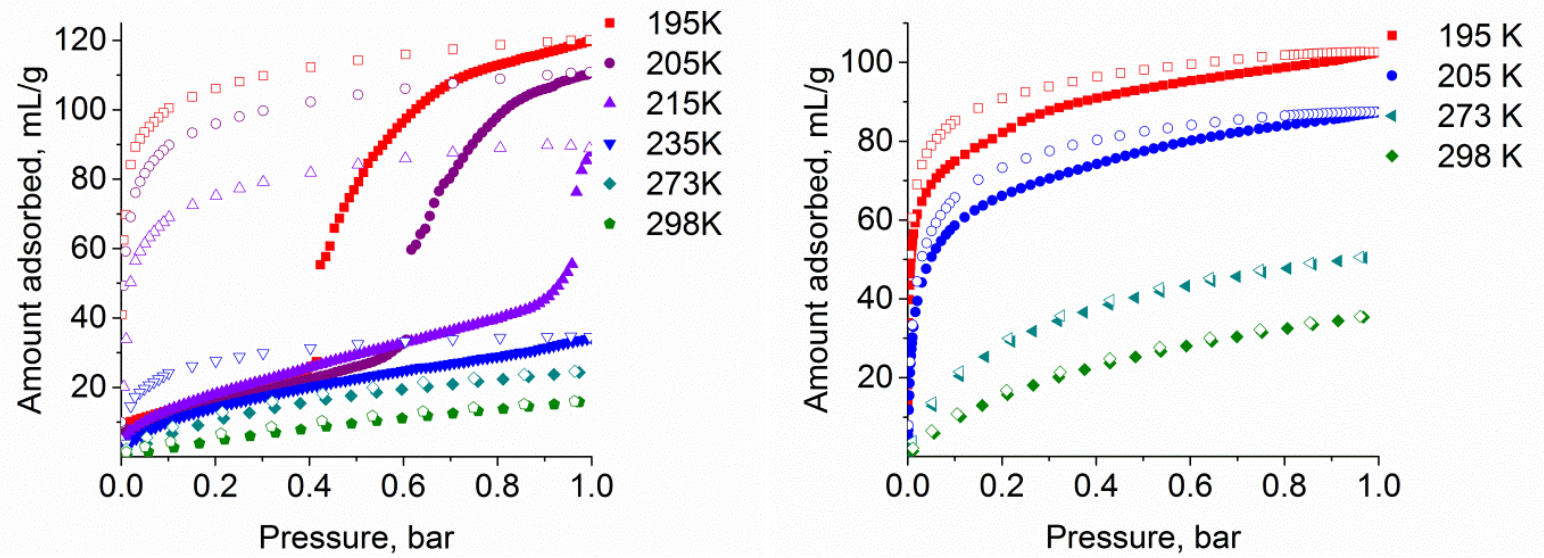

Figure 5. View of the adsorption (filled symbols) and desorption (open symbols) isotherms at different temperatures for $\mathrm{CO}_{2}$ in $\left[\mathrm{Mn}_{3}(\mathrm{Hpdc})_{2}(\mathrm{pdc})_{2}\right]$ (1) (left) and $\left[\mathrm{Mg}_{3}(\mathrm{Hpdc})_{2}(\mathrm{pdc})_{2}\right]$ (right).

The $\mathrm{CO}_{2}$ sorption isotherm at $195 \mathrm{~K}$ has two steps. The first step lies in the low-pressure region and is characterized by low gas uptake $\left(26.0 \mathrm{~mL} / \mathrm{g}\right.$ of $\mathrm{CO}_{2}$ at $\left.0.4 \mathrm{bar}\right)$. With increasing pressure there is a dramatic growth of the $\mathrm{CO}_{2}$ uptake reaching $119.9 \mathrm{~mL} / \mathrm{g}$ at $195 \mathrm{~K}$ and $1 \mathrm{bar}$. At the same time the gas-saturated sample of $\mathbf{1}$ demonstrates practically no desorption until the pressure drops to 0.1 bar, when an abrupt release of a large amount of $\mathrm{CO}_{2}$ takes place, resulting 
in a very high sorption/desorption hysteresis. The absorbed $\mathrm{CO}_{2}$ cannot be completely released even at low pressures, indicating a strong interaction between $\mathrm{CO}_{2}$ and the framework $\mathbf{1}$ at $195 \mathrm{~K}$ which could be described in terms of quadrupole interactions between guest molecules and the framework. ${ }^{43}$ Approximation of the desorption isotherm with a virial equation gives a surface area of $520 \mathrm{~m}^{2} \cdot \mathrm{g}^{-1}$ for $\mathbf{1}$ (Table 1). It is important to note all isotherms are fully reversible and reproducible for different batches of samples $\mathbf{1}$ and $\mathbf{2}$.

To quantitatively characterize the sorption hysteresis in $\mathbf{1}$ the hysteresis extent $(H E)$ was calculated as following:

$$
H E=\frac{S_{d e s}-S_{a d s}}{S_{a d s}} \cdot 100 \%=\frac{\int_{p} m_{d e s}(p) d p-\int_{p} m_{a d s}(p) d p}{\int_{p} m_{a d s}(p) d p} \cdot 100 \%
$$

where $m_{\text {des }}(p), m_{a d s}(p)$ are the uptake functions of pressure for desorption and adsorption respectively and $S_{\text {des, }}, S_{\text {ads }}$ are the areas under desorption and sorption corves in $m-p$ coordinates. The obtained values of HE are very high and are among the highest values obtained for the materials with huge hysteresis loops (Table 2).

Table 2. Hysteresis Extent in the sorption isotherms of $\mathrm{CO}_{2}$ in $\mathbf{1}$ and other MOFs at different temperatures.

\begin{tabular}{|l|l|l|l|}
\hline Compound Name/Formula & Temperature, $\mathrm{K}$ & $H E, \%$ & ref. \\
\hline 1 & 195 & 68 & \\
& 205 & 110 & This article \\
& 215 & 165 & \\
& 235 & 41 & \\
\hline
\end{tabular}




\begin{tabular}{|c|c|c|c|}
\hline $\begin{array}{l}{\left[\mathrm{Cu}_{2}(\mathrm{glu})_{2}(\mathrm{bpy})\right]} \\
{\left[\mathrm{Cu}_{2}(\mathrm{glu})_{2}(\mathrm{bpe})\right]} \\
{\left[\mathrm{Cu}_{2}(\mathrm{glu})_{2}(\mathrm{bpymh})\right]}\end{array}$ & $\begin{array}{l}298 \\
298 \\
298\end{array}$ & $\begin{array}{l}13 \\
21 \\
3\end{array}$ & 44 \\
\hline $\begin{array}{l}{\left[\mathrm{Zn}_{2}(\mathrm{DB}-\mathrm{bdc})_{2}(\mathrm{dabco})\right]} \\
{\left[\mathrm{Zn}_{2}(\mathrm{BPy}-\mathrm{bdc})_{2}(\mathrm{dabco})\right]}\end{array}$ & $\begin{array}{l}195 \\
195\end{array}$ & $\begin{array}{l}173 \\
70\end{array}$ & 45 \\
\hline BMOF-1-dcppy & 196 & 94 & 46 \\
\hline$[\mathrm{Zn}(\mathrm{glu})(\mu-\mathrm{bpe})]$ & 196 & 15 & 47 \\
\hline NOTT-202a & $\begin{array}{l}195 \\
221\end{array}$ & $\begin{array}{l}39 \\
0\end{array}$ & 48 \\
\hline JLU-Liu4 & 195 & 41 & 49 \\
\hline$\left\{\left[\mathrm{Co}_{2}(\mathrm{ndc})_{2}(\text { bpee })_{2}\right](\right.$ bpee $\left.)\right\}$ & 195 & 7 & 50 \\
\hline ITF-1 & 273 & 42 & 51 \\
\hline YO-MOF & 273 & 61 & 52 \\
\hline$\left[\mathrm{La}(\mathrm{btb})\left(\mathrm{H}_{2} \mathrm{O}\right)\right]$ & 278 & 37 & 53 \\
\hline
\end{tabular}

Notably, the second adsorption step is consistently observed when the $\mathrm{CO}_{2}$ adsorption reaches ca. $25 \mathrm{~mL} / \mathrm{g}$ corresponding to 1 molecule of $\mathrm{CO}_{2}$ per formula unit of 1 . The position of the hysteresis loop in the adsorption isotherm moves to higher pressure with increasing temperature, and results in a non-linear dependency of $H E$ with temperature (Table 2). $H E$ grows with temperature to reach a maximum of $165 \%$ at $215 \mathrm{~K}$. It then decreases to $41 \%$ at $235 \mathrm{~K}$ with no hysteresis observed at $298 \mathrm{~K}$. Generally the value of HE decreases linearly with pressure, with the position of the S-step shifting to the higher pressure region as in the case of NOTT-202a. ${ }^{44}$ The shift of the hysteresis loop also affects the sorption capacity of the material at 1 bar. Indeed, at $273 \mathrm{~K}$ and $235 \mathrm{~K} 1$ adsorbs $25.3 \mathrm{~mL} / \mathrm{g}$ and $34.3 \mathrm{~mL} / \mathrm{g}$ of $\mathrm{CO}_{2}$ respectively. Moreover, the hysteresis extent in 1 is comparable to $\left[\mathrm{Zn}_{2}(\mathrm{DB}-\mathrm{bdc})_{2}(\mathrm{dabco})\right]$, which has the highest reported 
$H E{ }^{41}$ The hysteretic sorption/desorption in the latter originates from a phase transition upon the introduction of $\mathrm{CO}_{2}$.

To investigate these possible structural rearrangements we performed in situ PXRD studies of activated 1 at $195 \mathrm{~K}$ (Figure S6) at 0, 0.25, 0.5 and 1 bar and then back to 0.5 bar and 0 . The PXRD analysis of $\mathbf{1}$ with $\mathrm{CO}_{2}$ revealed no phase transition. Thus, the value of $H E$ for $\mathbf{1}$ with $\mathrm{CO}_{2}$ is the highest for a material that does not undergo any phase-transformation during the adsorption/desorption cycle, and suggests the formation of stronger bonding to adsorbed $\mathrm{CO}_{2}$ molecules within the pore.

The previously reported microporous materials $\left[\mathrm{Mn}(\mathrm{HCOO})_{2}\right]^{54}$ and $\left[\mathrm{Mg}(\mathrm{HCOO})_{2}\right]^{55}$ have identical structures and demonstrate the same sorption behavior unlike compounds $\mathbf{1}$ and $\mathbf{2}$. The classical model of host-guest electrostatic interactions between $\mathrm{CO}_{2}$ and the framework cannot explain the origin of the high hysteresis in $\mathbf{1}$ and its absence in case of compound $\mathbf{2}$ as well. In order to explain the different gas sorption behavior in $\mathbf{1}$ and $\mathbf{2}$, we have performed the extensive DFT simulations of their $\mathrm{CO}_{2}$ adsorption. For both compounds, we tracked the energetics and the location of the adsorbed $\mathrm{CO}_{2}$ molecules by gradual molecule-by-molecule interaction with the framework to reveal the sorption pathway.

To begin with the most stable position for a single $\mathrm{CO}_{2}$ was determined among the various guest positions inside the MOF channel for $\mathbf{1}$ and $\mathbf{2}$ as shown on Figure S7. The results indicate that the $\mathrm{CO}_{2}$ molecule interacts differently in $\mathbf{1}$ and $\mathbf{2}$ at the initial stage of the sorption process. In the case of $\mathbf{1}$, the guest molecule is located parallel to the pyridine ring along the $b$ axis and lies perpendicular to $c$ axis as shown on Figure 6a. The charge density isosurface shows charge redistribution in the adsorbed $\mathrm{CO}_{2}$ molecule (Figure 6c) as well as significant charge redistribution in the host framework indicating a strong guest-host interaction with 
$\left[\mathrm{Mn}_{3}(\mathrm{Hpdc})_{2}(\mathrm{pdc})_{2}\right]$. In the case of compound 2, the guest molecule is located perpendicular to the pyridine ring lying in the $a c$ plane at a slight inclination due to a localized interaction between the carbon atom of $\mathrm{CO}_{2}$ and oxygen atom of the carboxyl group of nearest pyridinedicarboxylate ligand (Figure 6b). The excess charge is localized on both O-atoms of adsorbed $\mathrm{CO}_{2}$ and the carboxyl group of nearest pyridinedicarboxylic ligand; electron depletion occurs on the lower pyridinedicarboxylic ligand and on the C-atom of $\mathrm{CO}_{2}$ (Figure 6d). This results in a higher value for the energy of adsorption of $\mathrm{CO}_{2}$ in 2 at an uptake of 1 molecule per formula unit (see Table 3).

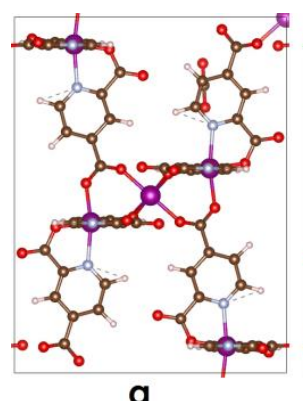

a

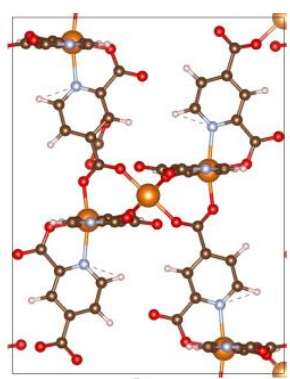

b

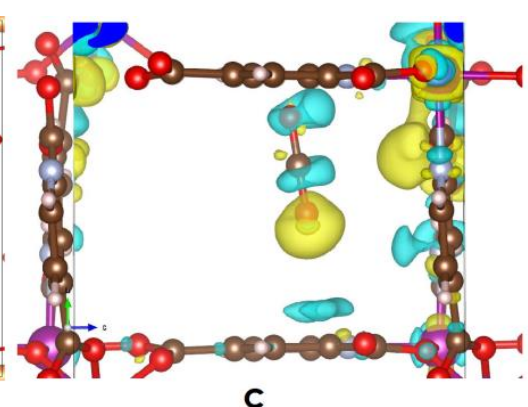

C

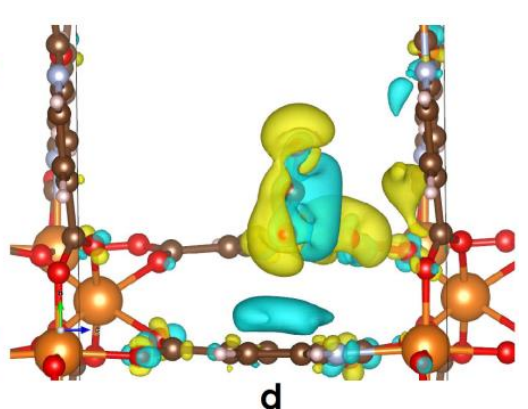

Figure 6. View of the most favorable intermolecular interactions and guest position of $\mathrm{CO}_{2}$ in (a) $\left[\mathrm{Mn}_{3}(\mathrm{Hpdc})_{2}(\mathrm{pdc})_{2}\right] \mathbf{1}$ and (b) $\left[\mathrm{Mg}_{3}(\mathrm{Hpdc})_{2}(\mathrm{pdc})_{2}\right]$ 2. Charge density isosurfaces for the interactions of $\mathrm{CO}_{2}$ with (c) $\left[\mathrm{Mn}_{3}(\mathrm{Hpdc})_{2}(\mathrm{pdc})_{2}\right] 1$ and (d) $\left[\mathrm{Mg}_{3}(\mathrm{Hpdc})_{2}(\mathrm{pdc})_{2}\right]$ 2. Yellow represents the accumulation of electron density and green the depletion of electron density. The DFT results are visualized using the VESTA code. 
Table 3. The adsorption energy $\left(E_{\mathrm{ads}}\right)$ of $\mathrm{CO}_{2}$ into $\left[\mathrm{Mn}_{3}(\mathrm{Hpdc})_{2}(\mathrm{pdc})_{2}\right]$ (1) and $\left[\mathrm{Mg}_{3}(\mathrm{Hpdc})_{2}(\mathrm{pdc})_{2}\right]$ (2) as calculated by DFT calculations. Values per single molecule are in parentheses.

\begin{tabular}{|c|c|c|}
\hline \multirow{2}{*}{ Entry of $\mathrm{n} \times$ Guest } & 1 & 2 \\
\hline & \multicolumn{2}{|c|}{$\mathrm{E}_{\mathrm{ads}} / \mathrm{kcal} / \mathrm{mol}$} \\
\hline $1 \times \mathrm{CO}_{2}$ & $-6.370(-6.370)$ & $-7.160(-7.160)$ \\
\hline $2 \times \mathrm{CO}_{2}$ & $-12.72(-6.360)$ & $-12.36(-6.180)$ \\
\hline $3 \times \mathrm{CO}_{2}$ & $-20.86(-6.953)$ & $-17.76(-5.920)$ \\
\hline $4 \times \mathrm{CO}_{2}$ & $-25.90(-6.475)$ & $-23.46(-5.865)$ \\
\hline
\end{tabular}

We then studied the gradual molecule-by-molecule interaction of the framework with guest $\mathrm{CO}_{2}$ molecules and the most stable configurations. The calculations revealed the presence of several $\mathrm{CO}_{2}$ adsorption sites I - IV (Figure 7) in the low pressures region. Sites I-IV are common for the both frameworks, however the order in which these sites are filled by $\mathrm{CO}_{2}$ molecules is different. In 2 the first $4 \mathrm{CO}_{2}$ molecules (per formula unit) form a chain-like. The chain-like $\mathrm{CO}_{2}$ superstructure was also observed for $\mathbf{1}$, yet the site III not I is the first that is occupied by guest $\mathrm{CO}_{2}$ molecule. The introduction of the next $\mathrm{CO}_{2}$ molecules into the framework results in rearrangement of the guest species with $\mathrm{CO}_{2}$ occupying the sites I and II. Thereupon a very similar chain to the one observed in $\mathbf{2}$ is formed at higher $\mathrm{CO}_{2}$ loadings. These interesting chainlike superstructures for $\mathrm{CO}_{2}$ are stabilized through guest-exchange interactions shown in Figure 7. 

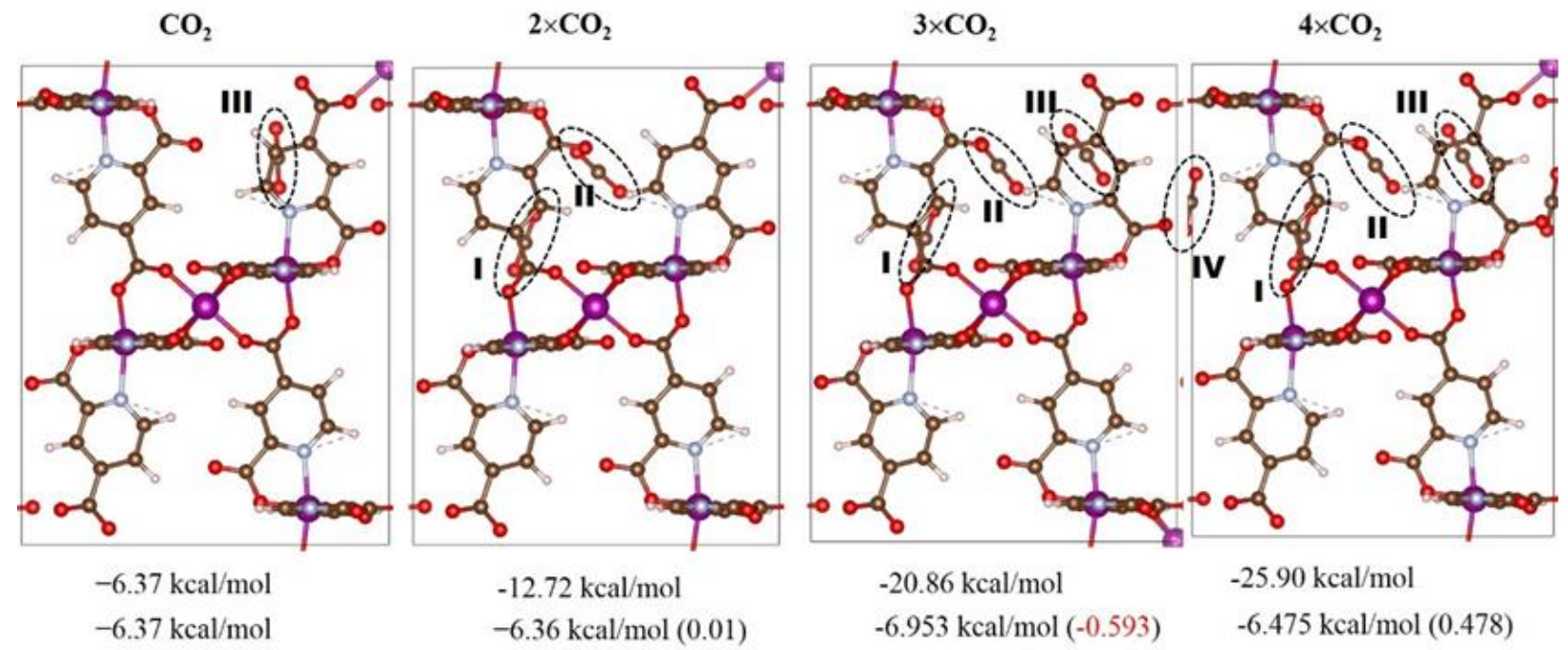

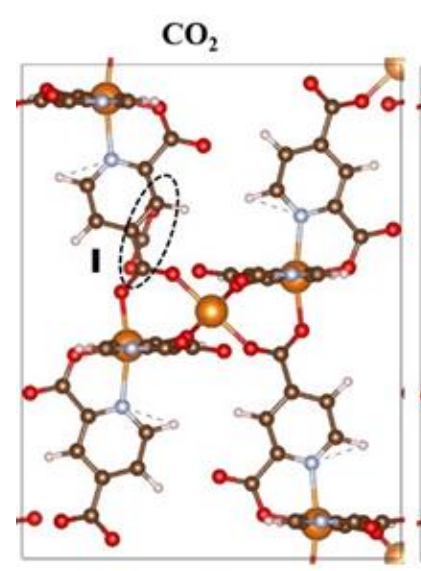

$-7.16 \mathrm{kcal} / \mathrm{mol}$

$-7.16 \mathrm{kcal} / \mathrm{mol}$

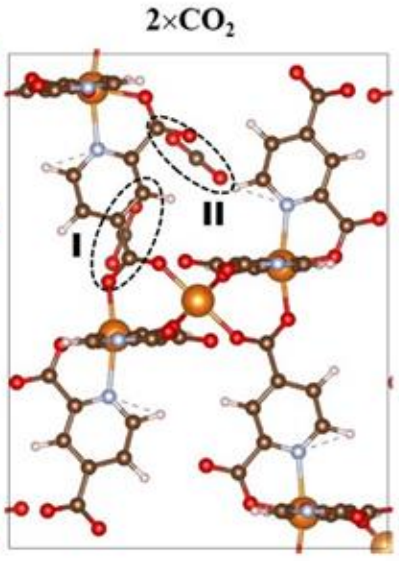

$-12.36 \mathrm{kcal} / \mathrm{mol}$

$-6.18 \mathrm{kcal} / \mathrm{mol}(0.98)$

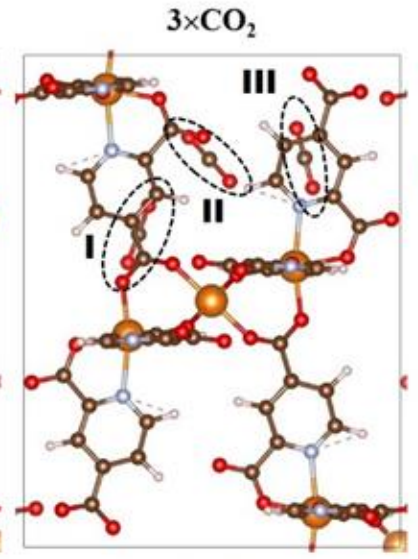

$-17.76 \mathrm{kcal} / \mathrm{mol}$

$-5.92 \mathrm{kcal} / \mathrm{mol}(0.26)$

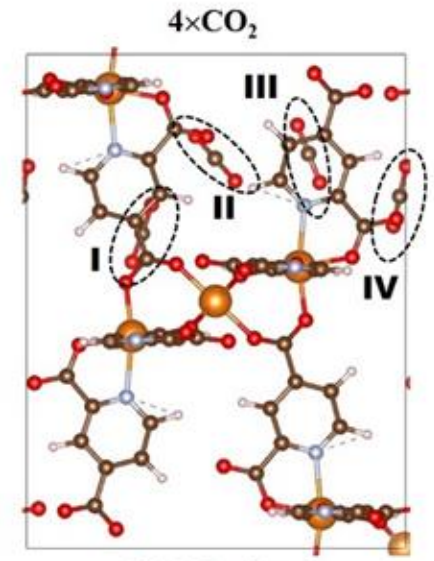

$-23.46 \mathrm{kcal} / \mathrm{mol}$

$-5.865 \mathrm{kcal} / \mathrm{mol}(-0.055)$

Figure 7. View of calculated adsorption sites in $\left[\mathrm{Mn}_{3}(\mathrm{Hpdc})_{2}(\mathrm{pdc})_{2}\right]$ (1) (up) and $\left[\mathrm{Mg}_{3}(\mathrm{Hpdc})_{2}(\mathrm{pdc})_{2}\right]$ (2) (bottom).

The charge density isosurface corresponds to the stable chain-like configuration achieved by electrostatic interactions via the excess and depletion of electron density localized on the O- and $\mathrm{C}$-atoms of $\mathrm{CO}_{2}$, respectively. Indeed, the importance of electrostatic interaction between $\mathrm{CO}_{2}$ proposed has been proposed previously, ${ }^{56,57}$ but never visualized in the manner shown on Figure 8. 


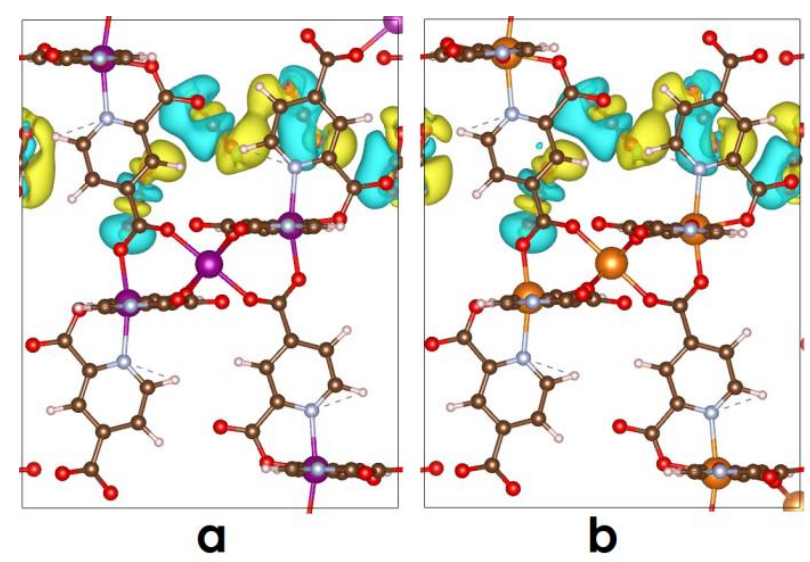

Figure 8. View of charge density isosurfaces for the guest-guest interactions of $4 \times \mathrm{CO}_{2}$ inside (a) $\left[\mathrm{Mn}_{3}(\mathrm{Hpdc})_{2}(\mathrm{pdc})_{2}\right] 1$ and $(\mathrm{b})\left[\mathrm{Mg}_{3}(\mathrm{Hpdc})_{2}(\mathrm{pdc})_{2}\right] 2$. Yellow represents the accumulation of electron density and green the depletion of electron density.

Importantly, $\mathbf{1}$ and $\mathbf{2}$ show different thermodynamics of formation of the $\mathrm{CO}_{2}$ chains. To understand this effect we plotted the energy difference of interaction between a single $\mathrm{CO}_{2}$ molecule and the two frameworks, and examined different possible positions of the guest species (Figure 9). To explain the clear difference in position of the first occupied site, as well as in the energetics of single-molecule adsorption sites 2 and 9 we performed additional calculations of local geometry and electronic structure of $\mathrm{CO}_{2}$. The data on partial density of states (PDOS) revealed compound 1 to demonstrate metallic features due to the presence of $3 d$ electrons from manganese atoms near the Fermi level (Figure S8, a), while compound $\mathbf{2}$ was found to be a semiconductor due to the absence of $d$-electrons (Figure $\mathrm{S} 8, b$ ). Given this, one can expect the lesser impact of metallic centers in $\mathbf{2}$ on the overall process of the adsorption. Indeed, the introduction of the $\mathrm{CO}_{2}$ molecules did not change significantly the electronic structure of the MOF complex (Figure S9), therefore we can assume pure electrostatic interaction between $\mathrm{CO}_{2}$ molecules and the framework plays a decisive role here. The largest overlapping between the $\mathrm{CO}_{2}$ molecular orbitals with the framework were found for the position 9 within the energy range 


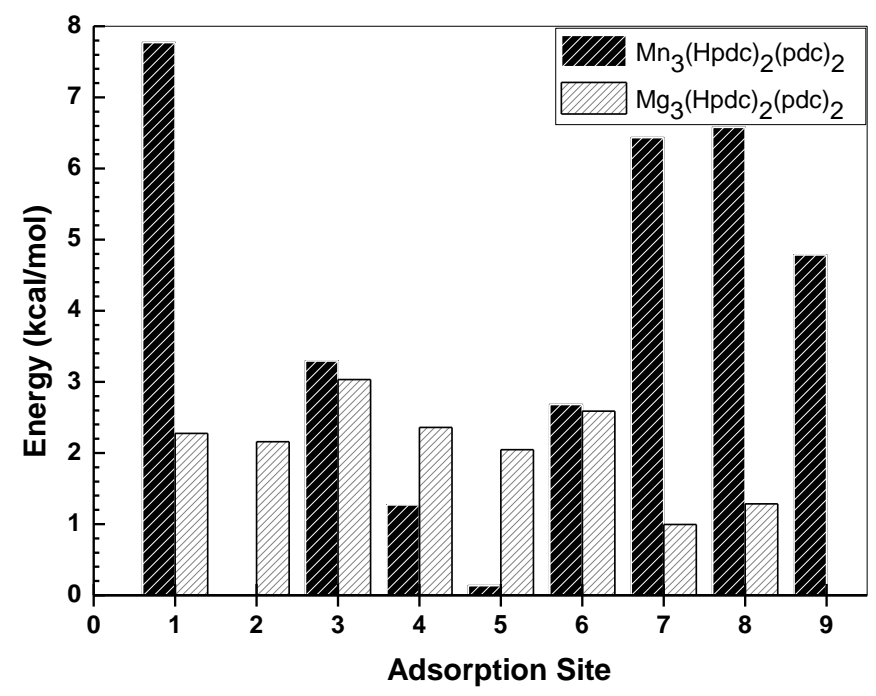

Figure 9. Comparison of interaction energy between single $\mathrm{CO}_{2}$ molecule adsorption at different sites in $\left[\mathrm{Mn}_{3}(\mathrm{Hpdc})_{2}(\mathrm{pdc})_{2}\right] \mathbf{1}$ (black) and $\left[\mathrm{Mg}_{3}(\mathrm{Hpdc})_{2}(\mathrm{pdc})_{2}\right] \mathbf{2}$ (grey).

between -10 and $-8 \mathrm{eV}$. As the geometry and charge analysis indicates, in this site a redistribution of the charge in the $\mathrm{CO}_{2}$ molecule occurs and it interacts with a framework in a such way, that the partially charged carbon $\mathrm{C}^{\delta+}$ and oxygen $\mathrm{O}^{\delta-}$ atoms of the adsorbed $\mathrm{CO}_{2}$ are aligned to ensure the most energetically favorable electrostatic interaction with the framework's partly charged nitrogen $\mathrm{N}^{\delta-}$ and carbon $\mathrm{C}^{\delta+}$ atoms (Figure S11, Table S4).

In case of compound $\mathbf{1}$ the manganese metal center plays a bigger role and therefore the adsorption has more complicated character and depends from the local charge distribution both in the framework and the guest molecule, involving some change of the charge at Mn atoms despite overall insignificant changes in the electronic structure (Figure S10). In this situation position 2 is more affordable. At this site, besides the alignment of negative $\mathrm{O}^{\delta-}$ atoms of $\mathrm{CO}_{2}$ in the proximity of partly positively charged carbon atoms of the framework, the guest molecule is also oriented to ensure the optimal distance to $\mathrm{Mn}(\mathrm{II})$ center (Figure S12, Table S5). 
Overall, the differences in adsorption energies between nearest adsorption sites 1 and 2 for compound $\mathbf{1}$ are caused by the local atomic charge distribution in pyridinedicarboxylate ligands. The less stable $\mathrm{CO}_{2}$ adsorption configuration for compound $\mathbf{1}$ at site 9 is made possible due to shorter distance between the molecule and the framework as opposed to compound $\mathbf{2}$. This leads to electrostatic repulsion between oxygen atom $\left(\mathrm{O}_{1}\right)$ of $\mathrm{CO}_{2}$ molecule and ligand's oxygen of the framework $\left(\mathrm{O}_{7}\right)$.

Furthermore, in the case of magnesium analogue 2, the difference in energy lies near 3 $\mathrm{kcal} / \mathrm{mol}$ indicating a rapid diffusion rate and more facile formation of the most thermodynamically affordable localization of $\mathrm{CO}_{2}$ inside the pore. The binding of subsequent $\mathrm{CO}_{2}$ molecules is accompanied by linear decrease in adsorption energy indicating a sorption pathway which is characteristic for type I isotherms, For $\mathbf{1}$, however, the difference in the hostguest interaction energy compared at different $\mathrm{CO}_{2}$ loadings reaches about $8 \mathrm{kcal} / \mathrm{mol}$ (Table 3). This suggests the presence of a particular diffusion barrier inside the pore at low $\mathrm{CO}_{2}$ loadings and low temperatures. Therefore, a very pronounced step is observed in the experimental adsorption isotherm and can be explained by the delay in the formation of the chain due to a low diffusion rate of $\mathrm{CO}_{2}$ within the MOF pore at temperatures below $235 \mathrm{~K}$. At higher temperatures the permeability within the framework increases, and the guest molecules can readily move within the pores and thus form the most thermodynamically stable guest superstructure (Figure 8). This explains why $\mathbf{1}$ demonstrates typical type I adsorption isotherm at temperatures above $235 \mathrm{~K}$.

Magnetic measurements of the framework 1 are another method to monitor the sorption process. Variable-temperature magnetic susceptibility measurements were performed over the temperature range $2-300 \mathrm{~K}$ and gave an effective magnetic moment value $\mu_{\mathrm{eff}}=9.77 \mu_{\mathrm{B}}$ for $\mathbf{1}$ at 
$300 \mathrm{~K}$, which is slightly lower than the spin-only value of $10.24 \mu_{\mathrm{B}}$ expected for three isolated paramagnetic high-spin $\mathrm{Mn}(\mathrm{II})$ ions $(\mathrm{S}=5 / 2, \mathrm{~g}=2$ ) (Figure $\mathrm{S} 13$ ). Upon cooling, the value of the effective magnetic moment decreases continuously and reaches $5.78 \mu_{\mathrm{B}}$ at $2 \mathrm{~K}$ which is in a good agreement with a theoretical value of $5.92 \mu_{\mathrm{B}}$ for one paramagnetic $\mathrm{Mn}(\mathrm{II})$ ion $(\mathrm{S}=5 / 2)$. The decrease of $\mu_{\text {eff }}$ values in $\mathbf{1}$ suggests antiferromagnetic interactions between the metal centers. The temperature-dependent magnetic susceptibility above 30K follows the Curie-Weiss law $\chi=$ $\mathrm{C} /(\mathrm{T}-\theta)$. The plot of $\chi^{-1}$ vs $\mathrm{T}$ gives a Curie constant $\mathrm{C}=13.22 \mathrm{~cm}^{3} \cdot \mathrm{K} \cdot \mathrm{mol}^{-1}$ and Weiss constant $\theta=-30.32 \mathrm{~K}$, slightly higher than values of known examples with similar composition. ${ }^{58-60}$ The trimer model (spin-Hamiltonian $\left.H=-2 J\left(S_{M n 1} S_{M n 2}+S_{M n 2} S_{M n 3}\right)\right)$ was used for the analysis of the $\mu_{\text {eff }}(\mathrm{T})$ dependence for $\mathbf{1}$. The best fit values of the g-factor and exchange coupling parameter $J$ are 1.99 and $-2.09 \mathrm{~cm}^{-1}$ (Figure S8).

Though Mg-containing analog $\mathbf{2}$ is not magnetically active, it is possible to partially substitute $\mathrm{Mg}$ centers in diamagnetic 2 with $\mathrm{Mn}$ (II) ions to generate the magnetically active $\left[\mathrm{Mn}_{\mathbf{x}} \mathrm{Mg}_{3-}\right.$ $\mathrm{x}(\mathrm{Hpdc})_{2}(\mathrm{pdc})_{2}$ ] containing low concentrations of magnetically active centers. This feature is very important for the investigation of $\mathrm{CO}_{2}$ sorption in the Mn-diluted framework $\left[\mathrm{Mn}_{\mathrm{x}} \mathrm{Mg}_{3-}\right.$ $\left.x(\operatorname{Hpdc})_{2}(\mathrm{pdc})_{2}\right]$ using EPR spectroscopy, which can monitor interactions between $\mathrm{CO}_{2}$ and the Mn centres within the host framework. The EPR spectrum of activated Mn-doped 2 contains 6 lines (Figure S14). Introduction of $1 \mathrm{CO}_{2}$ molecule slightly changes the shape of the peaks, and the observed broadening suggests a change in the strains (local distributions) of the hyperfine interaction constants either on $\mathrm{N}$ and $\mathrm{Mn}$ or solely on $\mathrm{N}$ centers. It should be noted that DFT simulations also revealed that the formation of the $\mathrm{CO}_{2}$ chain superstructure starts at the adsorption sites close to pyridine N-centres (Figure S7). Thus, EPR spectroscopic data bring good experimental evidence for the theoretical simulations. 
$\mathrm{N}$ centers can effectively interact with $\mathrm{CO}_{2}$ due to the high quadrupole moment of this gas, and therefore we argued that $\mathbf{1}$ and $\mathbf{2}$ may show selectivity to $\mathrm{CO}_{2}$ over $\mathrm{N}_{2}$ and $\mathrm{CH}_{4}$. Sorption/desorption isotherms for $\mathrm{N}_{2}$ and $\mathrm{CH}_{4}$ were recorded at 273 and $298 \mathrm{~K}$ and compared with corresponding isotherms for $\mathrm{CO}_{2}$ (Figure S15). Both 1 and 2 have low $\mathrm{N}_{2}$ capacity at ambient conditions, and the $\mathrm{N}_{2}$ uptake does not exceed $7 \mathrm{~mL} / \mathrm{g}$ even at $273 \mathrm{~K}$ and 1 bar. The selectivity for $\mathrm{CO}_{2} / \mathrm{N}_{2}$, defined as the ratio between the Henry constants (Table S6) are especially high for 2 at 49.8 at $273 \mathrm{~K}$ and 30.5 at $298 \mathrm{~K}$. The selectivity for $\mathrm{CO}_{2} / \mathrm{N}_{2}$ increases with increasing temperature for 1 from 4.6 at $273 \mathrm{~K}$ to 18.9 at $298 \mathrm{~K}$; we have observed a similar effect for other N-containing MOFs in the case of $\mathrm{C}_{2} \mathrm{H}_{2}$ vs $\mathrm{CO}_{2}$ selectivity. ${ }^{34}$ This may indicate that even at relatively high temperatures the guest-guest interactions for $\mathrm{CO}_{2}$ still strongly affect the sorption mechanism and modulate host-guest interactions. In 2 the sorption process is mostly governed by host-guest interactions and especially between the $\mathrm{N}$-centres of the $\mathrm{pzc}^{2-}$ ligand and guest $\mathrm{CO}_{2}$. This results in a higher selectivity and a characteristic decrease of selectivity with increasing temperature. $\mathrm{N}_{2}$ molecules interact weakly with both frameworks in $\mathbf{1}$ and $\mathbf{2}$ and with each other; thus, the observed selectivity is mostly dependent upon the $\mathrm{CO}_{2}$ adsorption energetics.

To model the performance of $\mathbf{1}$ and $\mathbf{2}$ in the separation of binary mixtures we also calculated the selectivity using ideal adsorbed solution theory (IAST) (Figure S16). ${ }^{61}$ For $1: 1 \mathrm{CO}_{2} / \mathrm{N}_{2}$ mixtures at 1 bar the selectivity factor for $\mathbf{1}$ is 2.8 at $273 \mathrm{~K}$ and 4.5 at $298 \mathrm{~K}$; for $\mathbf{2}$ they are 23.5 at $273 \mathrm{~K}$ and 19 at $298 \mathrm{~K}$. This analysis revealed good performance for 2 for $\mathrm{CO}_{2}$ extraction from mixtures with low (less than $20 \%$ ) $\mathrm{CO}_{2}$ content. As expected, 1 has somewhat lower selectivity for $\mathrm{CO}_{2}$ capture in comparison to 2 at low concentrations of $\mathrm{CO}_{2}$. 
The separation of $\mathrm{CO}_{2}$ and $\mathrm{CH}_{4}$ is another important industrial process. Both $\mathbf{1}$ and 2 demonstrate good performance in $\mathrm{CO}_{2} / \mathrm{CH}_{4}$ separation with selectivity factors reaching 8.0 at $273 \mathrm{~K}$ for 2 at $273 \mathrm{~K}$ and 1 bar (Table S7) based upon Henry's constant calculation. The selectivity factors decrease with temperature for both compounds (from 7.6 to 7.4 for $\mathbf{1}$, and from 8.0 to 7.2 for 2 ) $273 \mathrm{~K}$ and 1 bar. Interaction of $\mathrm{CH}_{4}$ with MOF surfaces is stronger than for $\mathrm{N}_{2}$, and therefore the Henry's constant for adsorption of $\mathrm{CH}_{4}$ is strongly temperature dependent. It also results in lower selectivity for $\mathrm{CO}_{2}$ than $\mathrm{N}_{2}$. The calculated enthalpy of adsorption at zero coverage is 26.0 and $24.5 \mathrm{~kJ} \cdot \mathrm{mol}^{-1}$ for $\mathrm{CO}_{2}$, and 25.3 and $21.8 \mathrm{~kJ} \cdot \mathrm{mol}^{-1}$ for $\mathrm{CH}_{4}$ for $\mathbf{1}$ and 2 , respectively.

IAST calculations also confirm that due to the higher energy of the $\mathrm{CH}_{4}-\mathrm{MOF}$ interaction, the selectivity of both compounds to $\mathrm{CO}_{2}$ is lower than for $\mathrm{N}_{2}$ mixture (Figure S17). For 1:1 $\mathrm{CO}_{2} / \mathrm{CH}_{4}$ at 1 bar the selectivity factors for 1 are 2.8 at $273 \mathrm{~K}$ and 2.5 at $298 \mathrm{~K}$, and 8.7 at $273 \mathrm{~K}$ and 9 at $298 \mathrm{~K}$ for 2.

\section{CONCLUSIONS}

Two metal-organic frameworks with unique adsorption properties have been prepared. The compounds show a high selectivity for $\mathrm{CO}_{2}$ with a very broad S-shaped hysteresis observed for $\mathrm{CO}_{2}$ adsorption in 1 . Theoretical modelling revealed the formation of unique chain $\mathrm{CO}_{2}$ superstructures within the channels of these porous compounds and confirmed the presence of 4 adsorption sites at low $\mathrm{CO}_{2}$ loadings for both compounds. Though their spatial arrangement is similar in both structures, the order in which local sites are filled by $\mathrm{CO}_{2}$ varies for each compound, resulting in significant differences in host-guest energetics. As a result a high 
diffusion barrier emerges in case of $\mathbf{1}$ which results in the observed S-shaped sorption isotherm. The theoretical calculations are supported experimentally by magnetic and EPR studies.

\section{ASSOCIATED CONTENT}

Supporting information for this article is given via the link at the end of this document.

\section{AUTHOR INFORMATION}

\section{Corresponding Author}

E-mail: sergei.sapchenko@manchester.ac.uk.

\section{Author Contributions}

"The first two authors contributed equally to this research work.

\section{ACKNOWLEDGMENTS}

The reported study was funded by RFBR according to the research project № 18-29-04001. R.V.B. is grateful to the crew of Center for Computational Materials Science and E-IMR center at the Institute for Materials Research, Tohoku University, for continuous support and also thankful to the Ministry of Education, Culture, Sports, Science, and Technology of Japan (Grant No. 17H03122) for financial support. EPR studies were supported by FASO (0333-2017-0002). A.M.S thanks RF President's grant MK-3272.2017.3 and FASO (0333-2017-0002). M.S. acknowledges support from the ERC (AdG 742041). 


\section{REFERENCES}

1. https://public.wmo.int/en/media/press-release/greenhouse-gas-concentrations-surge-newrecord.

2. UNEP (2016). The Emissions Gap Report 2016. United Nations Environment Programme (UNEP), Nairobi.

3. Wang, S.; Yan, S.; Ma, X.; Gong, J. Recent advances in capture of carbon dioxide using alkali-metal-based oxides. Energy Environ. Sci., 2011, 4, 3805-3819.

4. Bang, Y.; Han, S.-J.; Kwon, S.; Hiremath, V.; Song, I.-K.; Seo, J.-G. High Temperature Carbon Dioxide Capture on Nano-Structured $\mathrm{MgO}-\mathrm{Al}_{2} \mathrm{O}_{3}$ and $\mathrm{CaO}-\mathrm{Al}_{2} \mathrm{O}_{3}$ Adsorbents: An Experimental and Theoretical Study. J. Nanosci. Nanotechno., 2014, 14, 8531-8538.

5. Wang, K.; Zhao, P.; Guo, X.; Hai, D.; Chao, Y. High-temperature $\mathrm{CO}_{2}$ capture cycles of hydrated limestone prepared with aluminum (hydr)oxides derived from kaolin. Energ. Convers. Manage., 2014, 86, 1147-1153.

6. Dobrova, E. P.; Bratchikova, I. G.; Mikhalenko, I. I. Adsorption of carbon dioxide on tantalum oxide coated with palladium chloride. Russ. J. Phys. Chem., 2006, 80, 1528-1531.

7. Nambo, A.; He, J.; Nguyen, T. Q.; Atla, V.; Druffel, T.; Sunkara, M. Ultrafast Carbon Dioxide Sorption Kinetics Using Lithium Silicate Nanowires. Nano Lett., 2017, 17, 3327-3333.

8. Choi, S.; Drese, J.; Jones, C. Adsorbent Materials for Carbon Dioxide Capture from Large Anthropogenic Point Sources. Chem. Sus. Chem., 2009, 2, 796-854.

9. Kosinov, N.; Gascon, J.; Kapteijn, F.; Hensen, E. J. M. Recent developments in zeolite membranes for gas separation. J. Membrane Sci., 2016, 499, 65-79.

10. Majchrzak, A.; Nowak, W. Separation characteristics as a selection criteria of $\mathrm{CO}_{2}$ adsorbents. Journal of $\mathrm{CO}_{2}$ Utilization, 2017, 17, 69-79. 
11. Sreenivasulu, B.; Sreedhar, I.; Venugopal, A.; Reddy, B. M.; Raghavan, K. V. Thermokinetic Investigations of High Temperature Carbon Capture Using a Coal Fly Ash Doped Sorbent. Energ. Fuel., 2017, 31, 785-794.

12. Rashidi, N. A.; Yusup, S. An overview of activated carbons utilization for the postcombustion carbon dioxide capture. Journal of $\mathrm{CO}_{2}$ Utilization, 2016, 13, 1-16.

13. Adelodun, A. A.; Kim, K.-H.; Ngila, J. C.; Szulejko, J. A review on the effect of amination pretreatment for the selective separation of $\mathrm{CO}_{2}$. Appl. Energ., 2015, 158, 631-642.

14. Zhang, Z.; Yao, Z.-Z.; Xiang, S.; Chen, B. Perspective of microporous metal-organic frameworks for $\mathrm{CO}_{2}$ capture and separation. Energ. Environ. Sci., 2014, 7, 2868-2899.

15. Chaemchuen, S.; Kabir, N. A.; Zhou, K.; Verpoort, F. Metal-organic frameworks for upgrading biogas via $\mathrm{CO}_{2}$ adsorption to biogas green energy. Chem. Soc. Rev., 2013, 42, 93049332.

16. Belmabkhout, Y.; Guillerm, V.; Eddaoudi, M. Low concentration $\mathrm{CO}_{2}$ capture using physical adsorbents: Are metal-organic frameworks becoming the new benchmark materials? Chem. Eng. J., 2016, 296, 386-397.

17. Abu Ghalia, M.; Dahman, Y. Development and Evaluation of Zeolites and MetalOrganic Frameworks for Carbon Dioxide Separation and Capture. Energy Technology, 2017, 5, $356-372$.

18. Sreenivasulu, B.; Sreedhar, I.; Suresh, P.; Raghavan, K. V. Development Trends in Porous Adsorbents for Carbon Capture. Environ. Sci. Technol., 2015, 49, 12641-12661.

19. Zhou, K.; Chaemchuen, S.; Verpoort, F. Alternative materials in technologies for Biogas upgrading via $\mathrm{CO}_{2}$ capture. Renew. Sust. Energ. Rev., 2017, 79, 1414-1441. 
20. Zeng, Y.; Zou, R.; Zhao, Y. Covalent Organic Frameworks for $\mathrm{CO}_{2}$ Capture. Adv. Mater., 2016, 28, 2855-2873.

21. Olajire, A. A. Recent advances in the synthesis of covalent organic frameworks for $\mathrm{CO}_{2}$ capture. Journal of $\mathrm{CO}_{2}$ Utilization, 2017, 17, 137-161.

22. Vicent-Luna, J. M.; Luna-Triguero, A.; Calero, S. Storage and Separation of Carbon Dioxide and Methane in Hydrated Covalent Organic Frameworks. J. Phys. Chem. C, 2016, 120, $23756-23762$.

23. McDonald, T. M.; Mason, J. A.; Kong, X.; Bloch, E. D.; Gygi, D.; Dani, A.; Crocellà, V.; Giordanino, F.; Odoh, S. O.; Drisdell, W. S.; Vlaisavljevich, B.; Dzubak, A. L.; Poloni, R.; Schnell, S. K.; Planas, N.; Lee, K.; Pascal, T.; Wan, L.F.; Prendergast, D.; Neaton, J.B.; Smit, B.; Kortright, J. B.; Gagliardi, L.; Bordiga, S.; Reimer, J. A.; Long, J. R. Cooperative insertion of $\mathrm{CO}_{2}$ in diamine-appended metal-organic frameworks. Nature, 2015, 519, 303-308.

24. Bruker Advanced X-ray Solutions; Bruker AXS Inc.: Madison, WI, 2004.

25. Sheldrick, G. M. Crystal structure refinement with SHELXL. Acta Crystallogr., Sect. C: Struct. Chem., 2015, 71, 3-8.

26. Spek, A. L. PLATON SQUEEZE: a tool for the calculation of the disordered solvent contribution to the calculated structure factors. Acta Crystallogr., Sect. C: Struct. Chem., 2015, $71,9-18$.

27. Kresse, G.; Furthmüller, J. Efficiency of ab-initio total energy calculations for metals and semiconductors using a plane-wave basis set. Comput. Mater. Sci., 1996, 6, 15-50.

28. Kresse, G.; Furthmüller, J. Efficient iterative schemes for $a b$ initio total-energy calculations using a plane-wave basis set. Phys. Rev. B, 1996, 54, 11169-11186. 
29. Perdew, J. P.; Burke, K.; Ernzerhof, M. Generalized Gradient Approximation Made Simple. Phys. Rev. Lett., 1996, 77, 3865-3868.

30. Blöchl, P. E. Projector augmented-wave method. Phys. Rev. B, 1994, 50, 17953-17979.

31. Monkhorst, H. J.; Pack, J. D. Special points for Brillouin-zone integrations. Phys. Rev. B, 1976, 13, 5188-5192.

32. Grimme, S. Semiempirical GGA-type density functional constructed with a long-range dispersion correction. J. Comput. Chem., 2006, 27, 1787-1799.

33. Momma, K.; Izumi, F. VESTA 3 for three-dimensional visualization of crystal, volumetric and morphology data J. Appl. Crystallogr., 2011, 44, 1272-1276.

34. Sapchenko, S. A.; Dybtsev, D. N.; Samsonenko, D. G.; Belosludov, R. V.; Belosludov, V. R.; Kawazoe, Y.; Schröder, M.; Fedin, V. P. Selective gas adsorption in microporous metalorganic frameworks incorporating urotropine basic sites: an experimental and theoretical study. Chem. Commun., 2015, 51, 13918-13921.

35. Dybtsev, D. N.; Yutkin, M. P.; Samsonenko, D. G.; Fedin, V. P.; Nuzhdin, A. L.; Bezrukov, A. A.; Bryliakov, K. P.; Talsi, E. P.; Belosludov, R. V.; Mizuseki, H.; Kawazoe, Y.; Subbotin, O. S.; Belosludov, V. R. Modular, Homochiral, Porous Coordination Polymers: Rational Design, Enantioselective Guest Exchange Sorption and Ab Initio Calculations of HostGuest Interactions. Chem. Eur. J., 2010, 16, 10348-10356.

36. Tang, W.; Sanville, E.; Henkelman, G. A Grid-Based Bader Analysis Algorithm without Lattice Bias. J. Phys.: Condens. Matter, 2009, 21, No. 084204.

37. Sanville, E.; Kenny, S. D.; Smith, R.; Henkelman, G. An Improved Grid-Based Algorithm for Bader Charge Allocation. J. Comput. Chem., 2007, 28, 899-908. 
38. Henkelman, G.; Arnaldsson, A.; Jónsson, H. A Fast and Robust Algorithm for Bader Decomposition of Charge Density. Comput. Mater. Sci., 2006, 36, 354-360.

39. Yu, M.; Trinkle, D. R. Accurate and Efficient Algorithm for Bader Charge Integration. J. Chem. Phys., 2011, 134, No. 064111.

40. Brown, I. D. The Chemical Bond in Inorganic Chemistry: The Bond Valence Model, Oxford University Press, 2002.

41. Wei, Y.; Yu, Y.; Wu, K. Highly Stable Five-Coordinated Mn(II) Polymer $[\mathrm{Mn}(\text { Hbidc })]_{\mathrm{n}}($ Hbidc=1H-Benzimidazole-5,6-dicarboxylate): Crystal $\quad$ Structure, Antiferromegnetic Property, and Strong Long-Lived Luminescence. Cryst. Growth. Des., 2008, 8, 2087-2089.

42. Bai, Y.; Gao, H.; Dang, D.-B.; Guo, X.-Y.; An, B.; Shang, W.-L. A series of metalorganic frameworks based on polydentate Schiff-base ligands derived from benzil dihydrazone: synthesis, crystal structures and luminescent properties. Cryst. Eng. Comm., 2010, 12, 14221432.

43. Ju, P.; Jiang, L.; Lu, T.-B. A Three-Dimensional Dynamic Metal-Organic Framework with Fourfold Interpenetrating Diamondoid Networks and Selective Adsorption Properties. Inorg. Chem., 2015, 54, 6291-6295.

44. Bezuidenhout, C. X.; Smith, V. J.; Bhatt, P. M.; Esterhuysen, C.; Barbour, L. J. Extreme Carbon Dioxide Sorption Hysteresis in Open-Channel Rigid Metal-Organic Frameworks. Angew. Chem. Int. Ed., 2015, 54, 2079-2083.

45. Henke, S.; Schneemann, A.; Wutscher, A.; Fischer, R. A. Directing the Breathing Behavior of Pillared-Layered Metal-Organic Frameworks via a Systematic Library of Functionalized Linkers Bearing Flexible Substituents. J. Am. Chem. Soc., 2012, 134, 9464-9474. 
46. Dau, P. V.; Kim, M.; Garibay, S. J.; Münch, F. H. L.; Moore, C. E.; Cohen, S. M. SingleAtom Ligand Changes Affect Breathing in an Extended Metal-Organic Framework. Inorg. Chem., 2012, 51, 5671-5676.

47. Hwang, I. H.; Bae, J. M.; Hwang, Y.-K.; Kim, H.-Y.; Kim, C.; Huh, S.; Kim, S.-J.; Kim, Y. $\mathrm{CO}_{2}$ selective dynamic two-dimensional $\mathrm{Zn}^{\mathrm{II}}$ coordination polymer. Dalton Trans., 2013, 42, 15645-15649.

48. Yang, S.; Lin, X.; Lewis, W.; Suyetin, M.; Bichoutskaia, E.; Parker, J. E.; Tang, C. C.; Allan, D. R.; Rizkallah, P. J.; Hubberstey, P.; Champness, N. R.; Thomas, K. M.; Blake, A.J.; Schröder, M. A partially interpenetrated metal-organic framework for selective hysteretic sorption of carbon dioxide. Nat. Mater., 2012, 11, 710-716.

49. Wang, J.; Luo, J.; Zhao, J.; Li, D.-S.; Li, G.; Huo, Q.; Liu, Y. Assembly of Two Flexible Metal-Organic Frameworks with Stepwise Gas Adsorption and Highly Selective $\mathrm{CO}_{2}$ Adsorption. Cryst. Growth Des., 2014, 14, 2375-2380.

50. Saha, R.; Kumar, S. $\left\{\left[\mathrm{Co}_{2}(\text { ndc })_{2}(\text { bpee })_{2}\right](\right.$ bpee $\left.)\right\}:$ a $3 \mathrm{D}$ multifunctional MOF. Cryst. Eng. Comm., 2012, 14, 4980-4988.

51. Orcajo, G.; Calleja, G.; Botas, J. A.; Wojtas, L.; Alkordi, M. H.; Sanchez-Sanchez, M. Rationally Designed Nitrogen-Rich Metal-Organic Cube Material: An Efficient $\mathrm{CO}_{2}$ Adsorbent and $\mathrm{H}_{2}$ Confiner. Cryst. Growth Des., 2014, 14, 739-746.

52. Mulfort, K. L.; Farha, O. K.; Malliakas, C. D.; Kanatzidis, M. G.; Hupp, J. T. An Interpenetrated Framework Material with Hysteretic $\mathrm{CO}_{2}$ Uptake. Chem. Eur. J., 2010, 16, 276281.

53. Mu, B.; Li, F.; Huang, Y.; Walton, K.S. Breathing effects of $\mathrm{CO}_{2}$ adsorption on a flexible 3D lanthanide metal-organic framework. J. Mater. Chem., 2012, 22, 10172-10178. 
54. Samsonenko, D. G.; Kim, H.; Sun, Y.; Kim, G.-H.; Lee, H.-S.; Kim, K. Microporous Magnesium and Manganese Formates for Acetylene Storage and Separation. Chem. Asian J., 2007, 2, 484-488.

55. Dybtsev, D. N.; Chun, H.; Yoon, S. H.; Kim, D.; Kim, K. Microporous Manganese Formate: A Simple Metal-Organic Porous Material with High Framework Stability and Highly Selective Gas Sorption Properties. J. Am. Chem. Soc., 2004, 126, 32-33.

56. Walton, K. S.; Millward, A.R.; Dubbeldam, D.; Frost, H.; Low, J.L.; Yaghi, O. M.; Snurr, R. Q. Understanding Inflections and Steps in Carbon Dioxide Adsorption Isotherms in Metal-Organic Frameworks. J. Am. Chem. Soc., 2008, 130, 406-407.

57. Valenzano, L.; Civalleri, B.; Sillar, K.; Sauer, J. Heats of Adsorption of $\mathrm{CO}$ and $\mathrm{CO}_{2}$ in Metal-Organic Frameworks: Quantum Mechanical Study of CPO-27-M (M = Mg, Ni, Zn). J. Phys. Chem. C, 2011, 115, 21777-21784.

58. Wang, X.-W.; Dong, Y.-R.; Zheng, Y.-Q.; Chen, J.-Z. A Novel Five-Connected BN Topological Network Metal-Organic Framework Mn(II) Cluster Complex. Cryst. Growth Des., 2007, 7, 613-615.

59. Zheng, Y.-Q.; Xu, W.; Zhu, H.-L.; Lin, J.-L.; Zhao, L.; Dong, Y.-R. New pyridine-2,4,6tricarboxylato coordination polymers: Synthesis, crystal structures and properties. Cryst. Eng. Comm., 2011, 13, 2699-2708.

60. Ren, P.; Chen, P.-K.; Xu, G.-F.; Chen, Z. Novel $\left(4^{2} \cdot 8^{4}\right)\left(4^{3} \cdot 6^{3}\right)_{2}\left(4^{6} \cdot 6^{3} \cdot 8^{6}\right)_{2}$ topology network built up from the highly connective pyridine-2,4,6-tricarboxylate ligand. Inorg. Chem. Commun., 2007, 10, 836-838.

61. Myers, A. L.; Prausnitz, J. M. Thermodynamics of mixed-gas adsorption. AlChE J., 1965, 11, 121-127. 


\section{TOC Synopsis}

Pair of new isostructural microporous coordination frameworks $\left[\mathrm{Mn}_{3}(\mathrm{Hpdc})_{2}(\mathrm{pdc})_{2}\right](\mathbf{1})$ and $\left[\mathrm{Mg}_{3}(\mathrm{Hpdc})_{2}(\mathrm{pdc})_{2}\right](\mathbf{2})\left(\mathrm{pdc}^{2-}=\right.$ pyridine-2,4-dicarboxylate $)$ demonstrates completely different sorption behavior. While compound $\mathbf{2}$ has a typical type I shape $\mathrm{CO}_{2}$ isotherm, $\mathbf{1}$ features a twostep adsorption process with a very broad hysteresis between the adsorption and desorption curves. The combination of DFT calculations, sorption and XRD analysis explains this effect showing differences in host-guest and guest-guest interactions during $\mathrm{CO}_{2}$ adsorption process. 
TOC Graphic

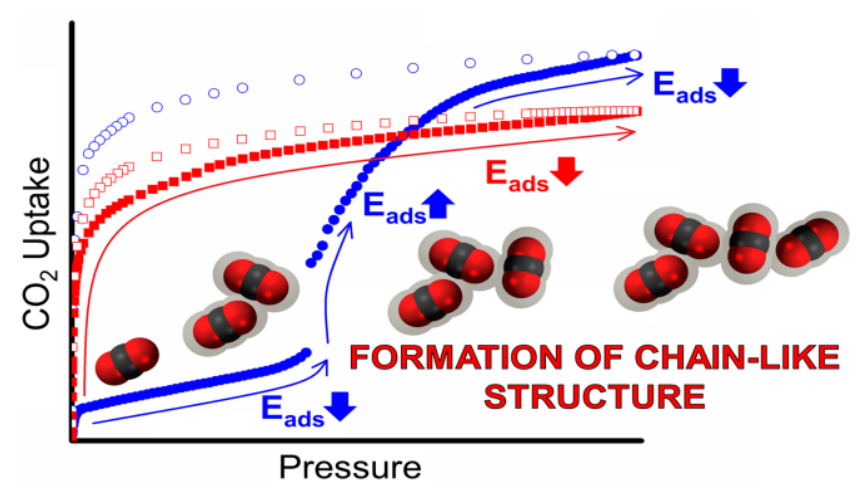

